\title{
Hydroxyapatite with Permanent Electrical Polarization: Preparation, Characterization and Response against Inorganic
} Adsorbates

\author{
Manuel Rivas, ${ }^{[a]}$ Luis J. del Valle, ${ }^{[a, b]}$ Elaine Armelin, ${ }^{[a, b]}$ Oscar Bertran, ${ }^{[c]}$ Pau Turon, ${ }^{* a, d]}$ Jordi \\ Puiggalí, ${ }^{*[a, b]}$ and Carlos Alemán*[a,b] \\ Dedication ((optional))
}

\begin{abstract}
Permanently polarized hydroxyapatite (HAp) particles have been prepared by applying a constant DC of $500 \mathrm{~V}$ at $1000{ }^{\circ} \mathrm{C}$ for $1 \mathrm{~h}$ to the sintered mineral. This process causes important chemical changes, as the formation of $\mathrm{OH}^{-}$defects (vacancies), the disappearance of hydrogenophosphate ions at the mineral surface layer, and structural variations reflected by the increment of the crystallinity. As a consequence, the electrochemical properties and electrical conductivity of the polarized mineral increase noticeably compared with as prepared and sintered samples. Moreover, these increments remain practically unaltered after several months. In addition, permanent polarization favours significantly the ability of HAp to adsorb inorganic bioadsorbates in comparison with as prepared and sintered samples. The adsorbates cause a significant increment of the electrochemical stability and electrical conductivity with respect to bare polarized HAp, which may have many implications for biomedical applications of permanently polarized HAp.
\end{abstract}

\section{Introduction}

Hydroxyapatite ( $\mathrm{HAp}), \mathrm{Ca}_{10}\left(\mathrm{PO}_{4}\right)_{6}(\mathrm{OH})_{2}$, is the major inorganic component of biological hard tissues such as bone and tooth. ${ }^{[1]}$ Synthetic HAp, which shows excellent ability to interact with living systems, has been investigated for biomedical applications, as for example drug and gene delivery, tissue engineering and bone repair. ${ }^{[2]}$

An important difference between amorphous calcium phosphate

[a] M. Rivas, Dr. L. J. del Valle, Dr. E. Armelin, Dr. P. Turon, Prof. Dr. J. Puiggalí, Prof. Dr. C. Alemán

Department of Chemical Engineering

Universitat Politècnica de Catalunya

EEBE, C/ Eduard Maristany 10-14, Ed. 12, 08019, Barcelona, Spain E-mail: jordi.puiggali@upc.edu and carlos.aleman@upc.edu

[b] M. Rivas, Dr. L. J. del Valle, Dr. E. Armelin, Dr. P. Turon, Prof. Dr. J. Puiggalí, Prof. Dr. C. Alemán

Barcelona Research Center for Multiscale Science and Engineering, Universitat Politècnica de Catalunya Institution

EEBE, C/ Eduard Maristany 10-14, Ed. 12, 08019, Barcelona, Spain

[c] Dr. O. Bertran

Department of Physics

Universitat Politècnica de Catalunya

EEI, Av. Pla de la Massa, 8, 08700 Igualada, Spain

[d] Dr. P. Turon

B. Braun Surgical, S.A

Carretera de Terrassa 121, 08191 Rubí (Barcelona), Spain

E-mail: pau.turon@bbraun.com
(ACP) and crystalline synthetic HAp (cHAp) is the alignment of the $\mathrm{OH}^{-}$ions along the $\mathrm{c}$-axis in the latter. The crystal structure of stoichiometric cHAp, which contains no $\mathrm{OH}^{-}$defects, is monoclinic at room temperature. ${ }^{[3]}$ However, the monoclinic cHAp changes to hexagonal phase at about $210{ }^{\circ} \mathrm{C}$, which means a change from an ordered to a disordered distribution of $\mathrm{OH}^{-}$ions along the $\mathrm{c}$-axis. The hexagonal phase becomes the most stable form of $\mathrm{cHAp}$ in the $\mathrm{pH}$ range of $4-12$ because of the disorder caused by the presence of vacancies and presence of $\mathrm{O}_{2}^{-}$ions in the columns of $\mathrm{OH}^{-}$groups. ${ }^{[3]}$ Although the properties of $\mathrm{cHAp}$ were altered by thermally-induced changes in the positions of $\mathrm{OH}^{-}$ions,${ }^{[4]}$ the observed effects were not stable at room temperature (i.e. the $\mathrm{OH}^{-}$reorientation has a short relaxation time).

ACP and cHAp interact with different phosphates and a biophosphonate (BPs), ${ }^{[5]}$ which is a very relevant topic in the field of biomaterials for biomedical applications. Thus, polyphosphate, which is an orthophosphate polymer found in mammalian organisms, ${ }^{[6]}$ promotes mineralization and bone regeneration when adsorbed onto HAp by stabilizing basic cell growth and differentiation. ${ }^{[7]}$ On the other hand, the oxygen atom that links the phosphate groups of pyrophosphates is replaced by a carbon atom in BPs, which results in the inhibition of both hydrolytic and enzymatic degradations. ${ }^{[8]}$ The affinity of BPs towards HAp has been associated with the formation of strong interactions between the two species. ${ }^{[9]}$ Indeed, BPs are primary agents in the current pharmacological arsenal against different bone diseases (e.g. osteoporosis, Paget disease of bone and metastatic bone malignancies). ${ }^{[10]}$

In the last decades, Yamashita and co-workers ${ }^{[11]}$ caused polarization effects in HAp samples by applying a constant DC electric field of $1.0-10.0 \mathrm{kV} / \mathrm{cm}$ at elevated temperature $(300-850$ $\left.{ }^{\circ} \mathrm{C}\right)$ to samples previously sintered at $1250{ }^{\circ} \mathrm{C}$ for $2 \mathrm{~h}$. Results indicated that the polarization effects were consequence of the electrical dipoles associated with the formation of defects inside crystal grains and of the space charge polarization originated in the grain boundaries. The slow relaxation of such dipoles suggested that polarization was only partially maintained (semipermanently), even though this effect was not quantified. In addition, the above mentioned thermally stimulated polarization process (TSP) was found to affect some surface properties as for example the wettability and adhesion of osteoblastic cells, which were higher onto semi-permanently polarized samples than onto non-polarized ones. ${ }^{[12]}$

In a very recent work, we used an alternative TSP strategy to prepare an electrophotocatalyst based on permanently polarized HAp particles. ${ }^{[13]}$ More specifically, the new catalyst 
allows fixing nitrogen from $\mathrm{N}_{2}$ and carbon from $\mathrm{CO}_{2}$ and $\mathrm{CH}_{4}$ to obtain both glycine and Alanine (D/L racemic mixture), the two simplest amino acids, using mild reaction conditions. In this work we disclose the enhanced electrochemical and electrical properties of permanently polarized cHAp comparing them with those of semi-permanently polarized samples, obtained using previously reported strategies. ${ }^{[1]}$ Furthermore, the adsorption of phosphates and phosphonate onto permanently polarized cHAp samples has been examined. Results reflect the significant impact of the alternative conditions used for the TSP treatment on the adsorption process. Our findings indicate that the adhesion of inorganic phosphates and phosphonates can be tailored by controlling the conditions used for cHAp treatment, suggesting new applications for permanently polarized $\mathrm{cHAp}$.

\section{Results and Discussion}

\section{Preparation and characterization}

HAp was prepared by adding $0.5 \mathrm{M}\left(\mathrm{NH}_{4}\right)_{2} \mathrm{HPO}_{4}$ in de-ionized water to $0.5 \mathrm{M} \mathrm{Ca}\left(\mathrm{NO}_{3}\right)_{2}$ in ethanol, as it is detailed in the Supporting Information. ${ }^{[14]}$ The resulting suspension was aged applying hydrothermal conditions (200 bar at $150{ }^{\circ} \mathrm{C}$ ) during $24 \mathrm{~h}$ to produce cHAp. Samples obtained at this stage has been denoted "as prepared", hereafter abbreviated cHAp/p. Sintered cHAp samples, hereafter denoted $\mathrm{cHAp} / \mathrm{s}$, were prepared by heating previously synthesized $\mathrm{cHAp} / \mathrm{p}$ at $1000{ }^{\circ} \mathrm{C}$ for $2 \mathrm{~h}$ in air. Finally, thermally stimulated polarized cHAp (cHAp/tsp) was achieved using discs of sintered samples $(10 \mathrm{~mm}$ of diameter $\times$ $1.68 \mathrm{~mm}$ of thickness), which were sandwiched between stainless steel (AISI 304) plates and polarized for $1 \mathrm{~h}$ under application of a constant DC voltage of $500 \mathrm{~V}$ (DC field of 3 $\mathrm{kV} / \mathrm{cm}$ ) at $1000{ }^{\circ} \mathrm{C}$. After this, samples were allowed to cool to room temperature, maintaining the $\mathrm{DC}$ voltage.

The FTIR spectra of as prepared, sintered and permanently polarized cHAp are compared in Figure 1a. The spectra, which show characteristic vibrational modes of $\mathrm{PO}_{4}^{3-}$ at $v_{1}=962 \mathrm{~cm}^{-1}$ and $v_{3}=1016,1087 \mathrm{~cm}^{-1}$, indicate that $\mathrm{cHAp} / \mathrm{tsp}$ does not undergo major changes with respect to $\mathrm{cHAp} / \mathrm{p}$ and $\mathrm{cHAp} / \mathrm{s}$. Analysis of WAXD measurements of as prepared and polarized samples were focused on peaks at $2 \theta=32^{\circ}-34^{\circ}$ (Figure $1 b$ ), which are characteristic of the (211), (112), and (300) cHAp reflections. The TSP process results in a very important increment of the crystallinity (i.e. from $0.43 \pm 0.01$ to $0.76 \pm 0.02$ ), which has been attributed to the formation of $\mathrm{OH}^{-}$defects. Fujimori et al. ${ }^{[15]}$ reported that $\mathrm{OH}^{-}$ions scape from the HAp matrix above $800^{\circ} \mathrm{C}$, such dehydration process resulting in the formation of vacancies and $\mathrm{O}^{2-}$ ions. In addition to the formation of a small amount of $\mathrm{OH}^{-}$defects, a monoclinic-to-hexagonal thermal phase transition occurs upon the application of such treatment to $\mathrm{cHAp} .^{[16]}$ The hexagonal phase becomes the most stable at room temperature because of the order-disorder phase transition, which is accounted for by the change in the position of the $\mathrm{OH}^{-}$ions.

The chemical composition, as determined by X-ray photoelectron spectroscopy (XPS), is consistent with the formation of thermally-induced $\mathrm{OH}^{-}$vacancies (Table $\mathrm{S} 1$ ): the content of oxygen is around 2 wt.\% lower for cHAp/s and $\mathrm{cHAp} / \mathrm{tsp}$ than for $\mathrm{cHAp} / \mathrm{p}$. Although the $\mathrm{Ca} / \mathrm{P}$ molar ratio of $\mathrm{cHAp} / \mathrm{p}$ is very close to the stoichiometric value of $1.67, \mathrm{cHAp} / \mathrm{s}$ and $\mathrm{cHAp} / \mathrm{tsp}$ exhibit a small reduction with respect to such ideal value (1.62 and 1.64, respectively), supporting the apparition of vacancies. Moreover, Figure 2a compares the XPS spectra in the $\mathrm{P} 2 \mathrm{p}$ and $\mathrm{Ca} 2 \mathrm{p}$ regions for $\mathrm{cHAp} / \mathrm{p}, \mathrm{cHAp} / \mathrm{s}$ and $\mathrm{cHAp} / \mathrm{tsp}$. The single $\mathrm{P} 2 p$ peak, which originates from $\mathrm{PO}_{4}^{3-}$ anions, ${ }^{[17]}$ is centered at $132.2 \mathrm{eV}$ for $\mathrm{cHAp} / \mathrm{p}$, experiencing a slight shift towards higher and lower energies $(\triangle \mathrm{BE}=+0.4$ and $-1.0 \mathrm{eV})$ after sintering and TSP, respectively. The binding energies of the $\mathrm{Ca} 2 \mathrm{p} 3 / 2$ and $\mathrm{Ca} 2 \mathrm{p} 1 / 2$ peaks, which are detected at 346.1 and $349.6 \mathrm{eV}$, respectively, for $\mathrm{cHAp} / \mathrm{p},{ }^{[17]}$ shift to 346.5 and $350.0 \mathrm{eV}$ for $\mathrm{cHAp} / \mathrm{s}$ and to 345.1 and $348.6 \mathrm{eV}$ for cHAp/tsp. These variations are consistent with structural changes associated to phase transitions.

(a)

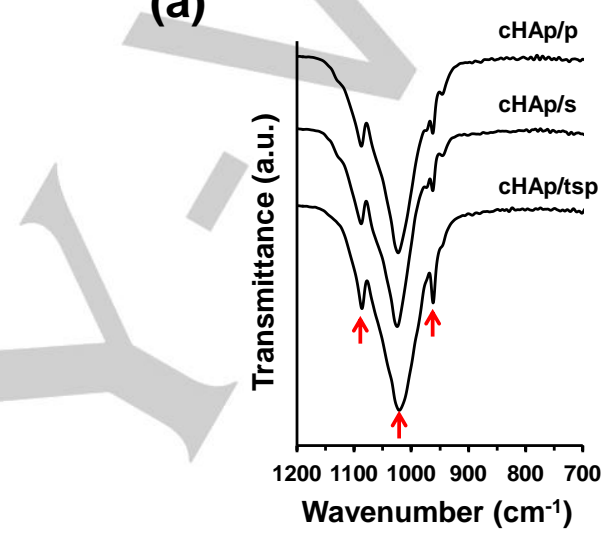

(b)

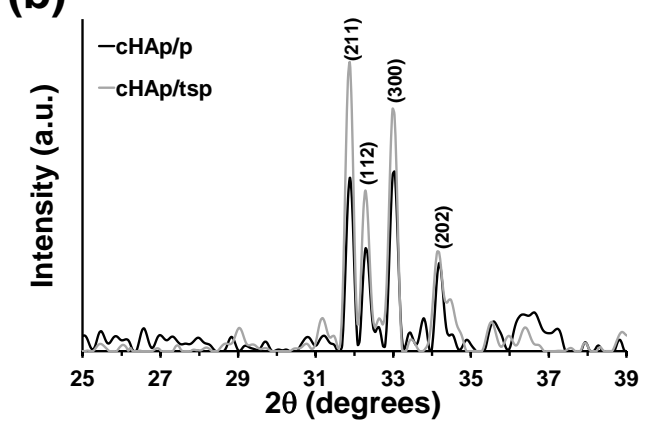

Figure 1. (a) FTIR spectra of as prepared, sintered and polarized. (b) X-ray diffraction patterns of $\mathrm{cHAp} / \mathrm{p}$ and $\mathrm{cHAp} / \mathrm{tsp}$. Samples were identified by the peaks at $2 \theta=32^{\circ}-34^{\circ}$.

Figure $2 b$ compares the solid state ${ }^{31} \mathrm{P}$ NMR spectra of $\mathrm{cHAp} / \mathrm{p}$ and $\mathrm{cHAp} / \mathrm{tsp}$, the spectrum of $\mathrm{cHAp} / \mathrm{s}$ being displayed in Figure S1. The main resonance peak in all samples (2.9 ppm) corresponds to bulk phosphate groups of HAp. ${ }^{[18]}$ This peak is narrower for $\mathrm{cHAp} / \mathrm{s}$ and $\mathrm{HAp} / \mathrm{tsp}$ than for $\mathrm{c} / \mathrm{HAp} / \mathrm{p}$, which is consistent with the increment of crystallinity mentioned above. The broad signals at approximately $[-1,0] \mathrm{ppm}$ and the shoulder at $[0,1] \mathrm{ppm}$ in both $\mathrm{cHAp} / \mathrm{p}$ and $\mathrm{cHAp} / \mathrm{s}$ are usually assigned to the lone protonated surfaces of phosphate groups arising from the disordered near surface layer. ${ }^{[19]}$ Indeed, cHAp particles are 
frequently described as an ordered crystalline core surrounded by a disordered non-apatitic surface layer. ${ }^{[20]}$ The shoulder at 4-6 $\mathrm{ppm}$ in $\mathrm{cHAp} / \mathrm{s}$ (Figure S1) has been attributed to the increment of $\mathrm{HPO}_{4}^{2-}$ ions at the disordered surface layer. ${ }^{[21]}$ However, the most amazing result is the single peak observed in cHAp/tsp, which corresponds to phosphate groups. This evidences that the TSP exerts an important effect on the surface layer. Thus, the fingerprints of the surface $\mathrm{OH}^{-}$ions leaving from the columns due to the TSP process are the disappearance of the surface $\mathrm{HPO}_{4}^{2-}$ ions and the formation of holes in the valence band to achieve the corresponding charge neutralization.

Figure 3 compares the surface morphologies of $\mathrm{cHAp} / \mathrm{p}$, $\mathrm{cHAp} / \mathrm{s}$ and $\mathrm{cHAp} / \mathrm{tsp}$. Although SEM micrographs of all samples are constituted by laminar crystals and fusiform rods, the amount of such elements increases upon the application of treatments, especially after TSP. Thus, crystals are bigger in $\mathrm{cHAp} / \mathrm{tsp}$ than in cHAp/p and cHAp/s, which is consistent with the crystallinity changes discussed above. The surface roughness $\left(R_{q}\right)$, as determined by contact profilometry, remained practically unaltered upon the application of thermal and TSP treatments (Table 1). (a)

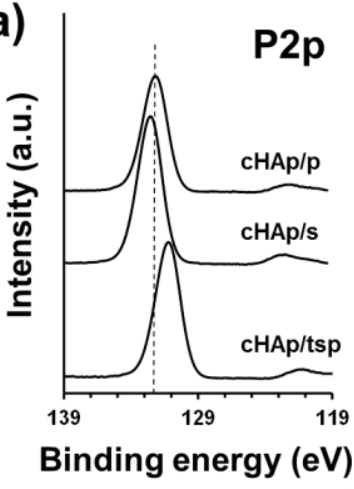

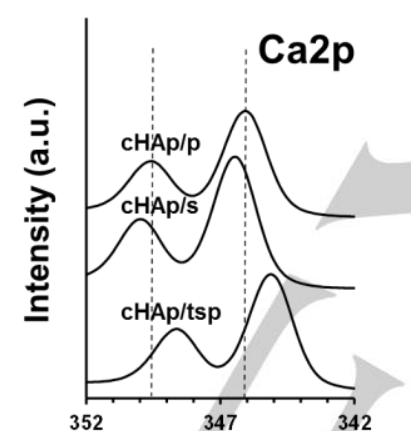

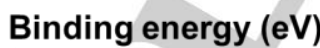

(b)

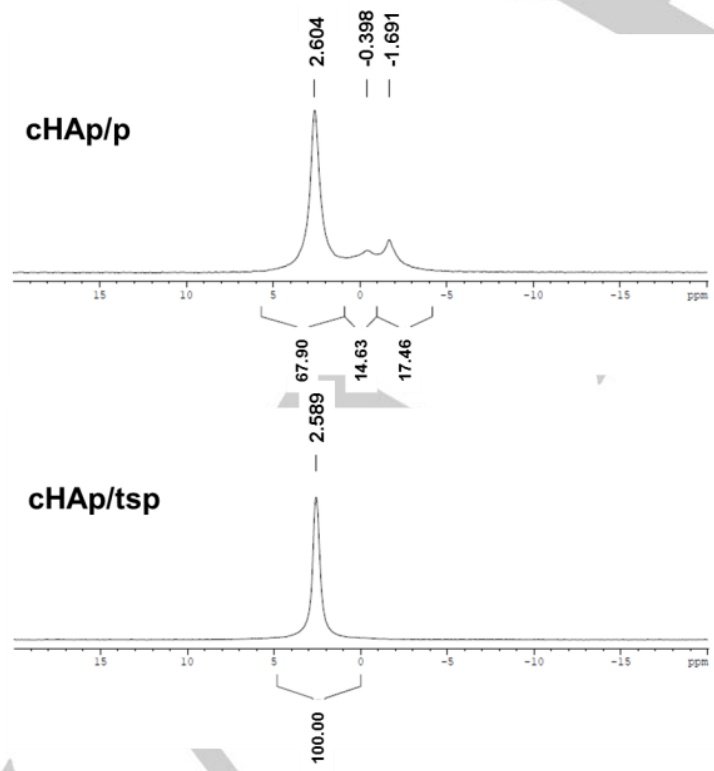

Figure 2. (a) High-resolution XPS spectra for cHAp samples: P2p and Ca2p regions. (b) Solid state ${ }^{31} \mathrm{P}$ NMR spectra of $\mathrm{cHAp} / \mathrm{p}$ and $\mathrm{cHAp} / \mathrm{tsp}$.

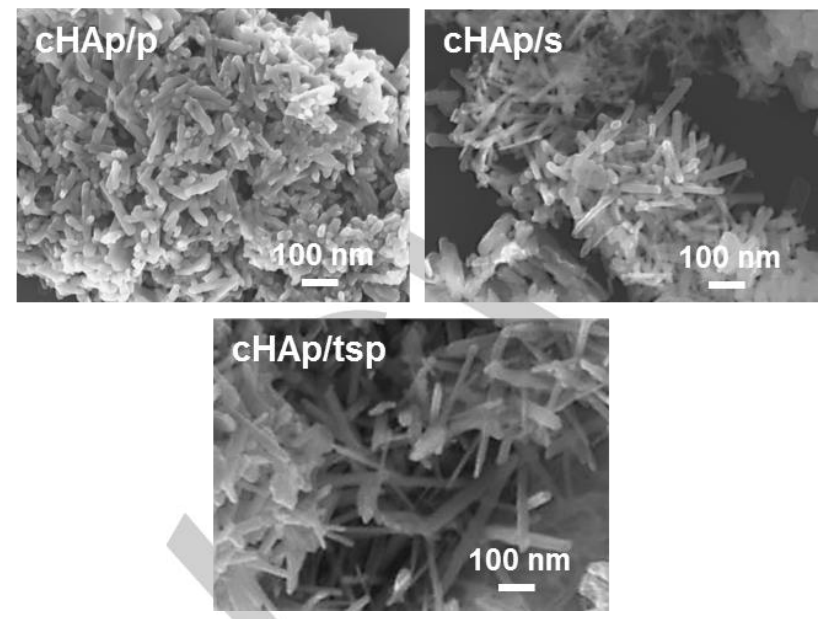

Figure 3. SEM micrographs of $\mathrm{cHAp} / \mathrm{p}, \mathrm{c} / \mathrm{HAp} / \mathrm{s}$ and $\mathrm{cHAp} / \mathrm{tsp}$ particles.

The contact angle of water $\left(\theta_{\text {water }}\right)$ was $\sim 4^{\circ}$ for $\mathrm{cHAp} / \mathrm{p}, \mathrm{cHAp} / \mathrm{s}$ and $\mathrm{cHAp} / \mathrm{tsp}$, indicating that the three are very hydrophilic materials, as it was expected because of their surface charge. In contrast, the contact angle of fetal bovine serum $\left(\theta_{F B S}\right)$ was significantly lower on cHAp/s and, especially, cHAp/tsp than on $\mathrm{cHAp} / \mathrm{p}$ (Table 1). This variation suggests that the reorganization of the ions induced by the thermal and TSP treatments increases the contribution of the polar component to the surface energy.

Table 1. Roughness $\left(R_{\mathrm{q}}\right)$ and contact angle of water and fetal bovine serum drops $\left(\theta_{\text {water }}\right.$ and $\left.\theta_{\mathrm{FBS}}\right)$ determined for $\mathrm{cHAP} / \mathrm{p}, \mathrm{cHAp} / \mathrm{s}$ and $\mathrm{cHAp} / \mathrm{tsp}$ samples.

\begin{tabular}{llll} 
Sample & $\mathrm{Rq}(\mathrm{nm})$ & $\theta$ water $(\stackrel{\circ}{)})$ & $\theta \mathrm{FBS}(\stackrel{\circ}{)})$ \\
\hline $\mathrm{cHAp} / \mathrm{p}$ & $851 \pm 194$ & $3 \pm 1$ & $81 \pm 2$ \\
$\mathrm{cHAp} / \mathrm{s}$ & $863 \pm 158$ & $4 \pm 1$ & $61 \pm 2$ \\
$\mathrm{cHAp} / \mathrm{tsp}$ & $882 \pm 92$ & $4 \pm 1$ & $51 \pm 2$ \\
\hline
\end{tabular}

Electrochemical properties: permanent vs. semi-permanent polarization

Cyclic voltammograms recorded in phosphate buffer saline solution (PBS; pH 7.2) for cHAp/p, cHAp/s and cHAp/tsp fixed on steel are compared in Figure 4a. Although cHAp/p exhibits higher electrochemical activity than bare steel (blank), the electroactivity increases considerably with thermal and TSP treatments (i.e. $46 \%$ and $150 \%$, respectively). In the case of cHAp/tsp, such effect is accompanied of a significant enhancement of the anodic current intensity at the reversal potential. Thus, results evidence that the structural changes caused by the TSP treatment facilitate the diffusion of ions through the inorganic matrix and, therefore, the electrochemical response upon oxidation-reduction processes.

Treatments also affect the electrochemical stability, as is shown by the loss of electroactivity ( $L E A$; Eqn S3) with the number of consecutive oxidation-reduction (redox) cycles 
(Figure 4b). The electroactivity of all samples decreases rapidly during the first $100-150$ redox cycles, experiencing a very slow reduction along the next cycles. After 1000 cycles, the electroactivity decreased $72 \%, 67 \%$ and $60 \%$ for cHAp/p, $\mathrm{cHAp} / \mathrm{s}$ and $\mathrm{cHAp} / \mathrm{tsp}$, respectively, evidencing that structural changes caused by the TSP process enhances the stability of the electrochemical properties.

The behaviour followed by the specific capacitance ( $S C$; Eqn S4) is fully consistent with that of the electroactivity. Although $S C$ was small in all cases, the ability to store charge of $\mathrm{cHAp} / \mathrm{p}$ $(S C=160 \mu \mathrm{F} / \mathrm{g}$ ) resulted $71 \%$ and $82 \%$ smaller than those of $\mathrm{cHAp} / \mathrm{s}$ and $\mathrm{cHAp} / \mathrm{tsp}(S C=560$ and $890 \mu \mathrm{F} / \mathrm{g}$, respectively). Also, the variation of the specific capacitance with the number of redox cycles (Figure 4c) was similar to that described above for LEA.

(a)

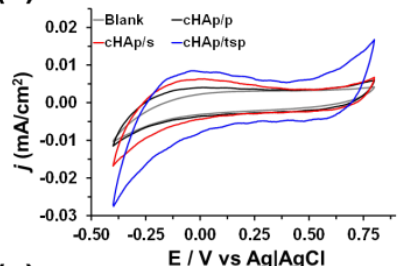

(c)

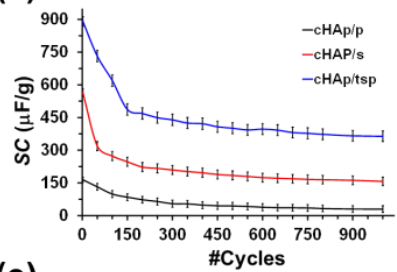

(e)

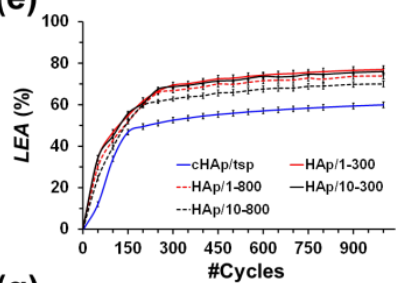

(g)

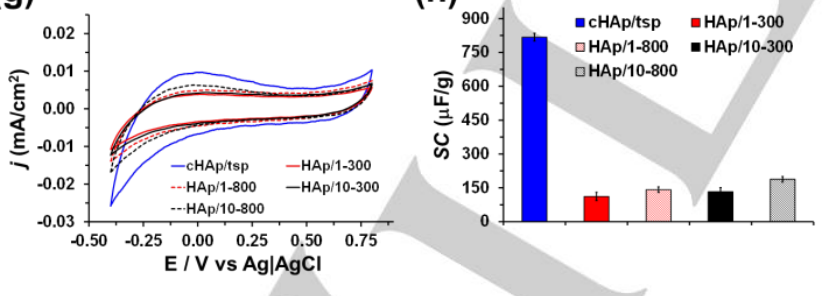

Figure 4. (a) Control voltammograms and variation of both (b) the loss of electroactivity (LEA; Eqn S3) and (c) the specific capacitance (SC; Eqn S4) against the number of redox cycles in PBS ( $\mathrm{pH} 7.2)$ for $\mathrm{cHAp} / \mathrm{p}, \mathrm{c} / \mathrm{HAp} / \mathrm{s}$ and cHAp/tsp. The voltammogram of bare steel (blank) is included in (a). (d-f) Comparison between the electrochemical properties of permanently polarized cHAp/tsp and different semi-permanently polarized HAp samples: (d) control voltammograms in PBS, (e) LEA against number of redox cycles, and (f) $S C$ in PBS ( $\mathrm{pH}$ 7.2). The labelling of the semi-permanently polarized HAp samples is described in the text. (g-h) Comparison between semi-permanently polarized and $\mathrm{cHAp} / \mathrm{tsp}$ samples prepared 3 months before the measurements: $(\mathrm{g})$ control voltammograms and (h) SC in PBS (pH 7.2). The scan rate was 50 $\mathrm{mV} / \mathrm{s}$ in all cases.
In order to examine the influence of the preparation conditions in the electrochemical properties, semi-permanently polarized HAp samples were prepared following the procedure described by Yamashita and co-workers. ${ }^{[11]}$ This can be summarized as follows: (i) HAp was synthesized by chemical precipitation; (ii) prepared HAp was dried at $850{ }^{\circ} \mathrm{C}$ for $2 \mathrm{~h}$; (iii) dried HAp was sintered in saturated water vapor atmosphere at $1250^{\circ} \mathrm{C}$ for $2 \mathrm{~h}$; and (iv) sintered samples were electrically polarized in a $\mathrm{DC}$ field of $1 \mathrm{kV} / \mathrm{cm}$ at $300^{\circ}$ or $800{ }^{\circ} \mathrm{C}$ for $1 \mathrm{~h}$ (hereafter $\mathrm{HAp} / 1-300$ or $\mathrm{HAp} / 1-800$, respectively) or a DC field of $10 \mathrm{kV} / \mathrm{cm}$ at $300{ }^{\circ} \mathrm{C}$ or $850^{\circ} \mathrm{C}$ for $1 \mathrm{~h}$ (hereafter HAp/10-300 or HAp/10-850, respectively). It is worth noting that the $\mathrm{DC}$ field values ( 1 and 10 $\mathrm{kV} / \mathrm{cm}$ ) and the polarization temperatures (300 and $800{ }^{\circ} \mathrm{C}$ ) were selected to include the most diverse conditions employed for the preparation of semi-permanently polarized HAp. ${ }^{[11]}$

The voltammograms recorded for cHAp/tsp, HAp/1-300, $\mathrm{HAp} / 1-800, \mathrm{HAp} / 10-300$ and $\mathrm{HAp} / 10-800$ samples after 20 consecutive oxidation-reduction cycles are compared in Figure $4 \mathrm{~d}$. The electrochemical activity of $\mathrm{cHAp} / \mathrm{tsp}$ is at least $20 \%$ higher than that of the rest of the samples. Moreover, anodic and cathodic current densities at the final and reversal potentials, respectively, are significantly higher in absolute values for cHAp/tsp than for the other samples, reflecting a higher movement of charge during the oxidation and reduction processes. This feature is particularly noticeable for the anodic current density (i.e. $16.8 \mu \mathrm{A} / \mathrm{cm}^{2}$ for $\mathrm{cHAp} / \mathrm{tsp}$ while a value comprised between 4 and $9 \mu \mathrm{A} / \mathrm{cm}^{2}$ for the other samples). Besides, the electrochemical stability and $S C$ are considerably higher for $\mathrm{cHAp} / \mathrm{tsp}$ than for semi-permanently polarized HAp samples (Figures $4 \mathrm{e}$ and $4 \mathrm{f}$ ).

Results displayed in Figures $4 d$-f are fully consistent with the highly crystalline organization and regular surface structure of cHAp/tsp. Indeed, the crystallinity of HAp/1-300, HAp/1-800, $\mathrm{HAp} / 10-300$ and HAp/10-800, as determined from the corresponding WAXD patterns, was lower than $0.63 \pm 0.02$, while cHAp/tsp exhibited a crystallinity of $0.76 \pm 0.02$. Moreover, the electrochemical behavior of semi-permanently polarized HAp samples is, independently of the polarization conditions (i.e. DC field and temperature), very similar to that displayed by $\mathrm{cHAp} / \mathrm{s}$ (Figures 4a-c), suggesting that application of a water vapor stream during the sintering process and/or the low temperature applied during the polarization process $(\leq 800 \stackrel{\circ}{\circ}$ ) do not inhibit the formation of disordered near surface layers with protonated phosphate groups. This lack of organization also affects the preservation of the electrochemical properties induced by the polarization process. This is reflected in Figures $4 \mathrm{~g}-\mathrm{h}$, which compare the voltammograms and $S C$ of samples measured 3 months after being prepared and polarized. During such period, all samples were stored in the lab at room temperature under atmospheric conditions. As it can be seen, the electrochemical activity and SC of HAp/1-300, HAp/1-800, HAp/10-300 and $\mathrm{HAp} / 10-800$ samples are very similar, suggesting that the distinctive properties induced by the magnitude of the DC field and the polarization temperature disappears after 3 months only. Indeed, the differences between such samples and $\mathrm{cHAp} / \mathrm{p}$ (Figures $4 \mathrm{a}$ and $4 \mathrm{c}$ ) are very small, which prove that the polarization effects induced by the conditions described by 
Yamashita and co-workers ${ }^{[11]}$ are not enduring over time. In contrast, the properties of cHAp/tsp samples remain practically unchanged after three months (e.g. the SC decreased by $9 \%$ only), demonstrating that temperatures higher than $800{ }^{\circ} \mathrm{C}$ are crucial to achieve permanent polarization effects.

Electrical properties: permanent vs. semi-permanent polarization Electrochemical impedance spectroscopy (EIS) measurements were carried out to evaluate the ionic conductivity. This technique is expected to provide relevant information about the influence of the sintering and TSP processes in the resistivity of cHAp. Figure 5a compares representative and reproducible Nyquist plots obtained for $\mathrm{cHAp} / \mathrm{p}, \mathrm{cHAp} / \mathrm{s}$ and $\mathrm{cHAp} / \mathrm{tsp}$. In a Nyquist plot, the first semi-circular response corresponds to the electron transfer resistance at the higher frequency range, which controls the electron transfer kinetics of the redox probe on the electrode-solid disk interface. The diameter of the semi-circle defines the resistance of electron transfer, usually called bulk resistance $\left(R_{b}\right)$. The Nyquist plot recorded for $\mathrm{cHAp} / \mathrm{p}$ exhibits only one dielectric relaxation time $\left(\tau_{1}\right)$, which corresponds to a single charge transfer across the solid disk, showing that the material has a high bulk resistance (i.e. low ionic conductivity) in the dry state. Bode plots (Figure S2) show a phase angle close to $80^{\circ}$, which correspond to resistive materials in the dry state. The semi-circle diameter in Nyquist plots is much smaller for $\mathrm{cHAp} / \mathrm{s}$ and, especially, for cHAp/tsp. Besides, a second time constant $\left(\tau_{2}\right)$ appears due to the significant structural modification occurred in cHAp, enabling fast charge transport across the disk. As discussed above, cHAp/s and cHAp/tsp present higher crystallinity and bigger crystals than $\mathrm{cHAp} / \mathrm{p}$. Therefore, the thermal treatment step promotes the growing of the crystals, while the TSP treatment is, apparently, responsible of the definition of good pathways for charge transportation.

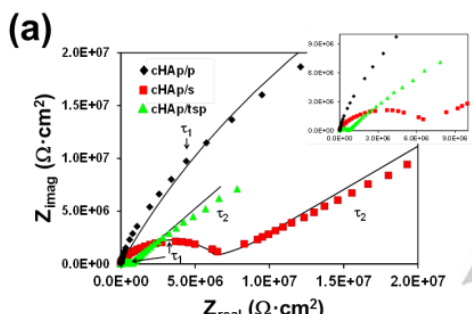

(b)

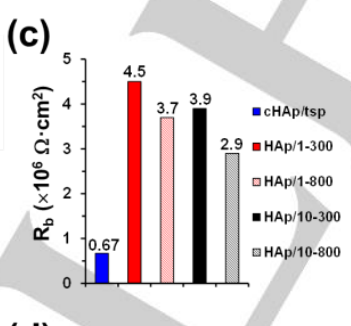

(d)

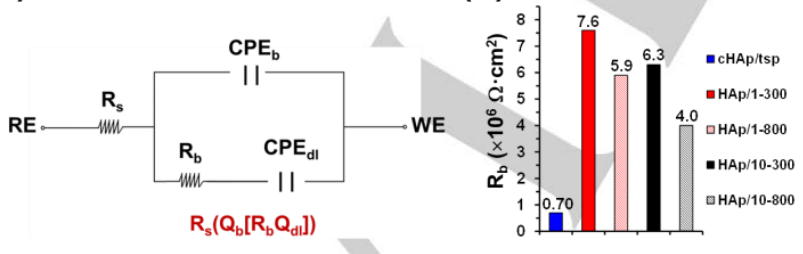

Figure 5. (a) Nyquist plots for $c H A p / p, c H A p / s$ and cHAp/tsp. The inset represents the Nyquist behavior at high frequency. (b) Electrical equivalent circuit (EEC) used to fit the experimental data recorded for $\mathrm{cHAp} / \mathrm{s}$ and cHAp/tsp: $R_{S}$ is the electrolyte resistance, $C P E_{b}$ and $R_{b}$ are the bulk constant phase element and resistance, respectively, $C P E_{d \mid}$ is the contribution of the double layer capacitance. (c,d) Comparison between the $R_{b}$ values determined by EIS for permanently and semi-permanently polarized HAp samples: (c) fresh samples and (d) samples prepared using the same procedure that fresh samples and left in a dry environment for 3 months before the measurements.
The electrical equivalent circuit (EEC) used to fit the experimental data is shown in Figure $5 \mathrm{~b}$. The EEC contains three important elements: $R_{b}$ that represents the bulk resistance; and $Q_{b}$ and $Q_{d l}$ that describes the ideal capacitances from both the $\mathrm{CHAp}$ thick disk and the double layer between the metal-disk surfaces, respectively. $\mathrm{R}_{\mathrm{S}}$ corresponds to the electrolyte resistance, even though it was considered $\sim 0 \Omega \cdot \mathrm{cm}^{2}$ due to the absence of liquid electrolyte. The $C P E_{b}$ is the real capacitance of the bulk disk, which accounts for the non-uniform diffusion among the films adhered to the electrode surface. On the other hand, $\mathrm{CPE}_{d l}$ is the real capacitance of the double-layer, which in turn is typically associated to the surface reactivity, surface heterogeneity and roughness (i.e. related to the electrode geometry and porosity). Also, the CPE impedance, which has been expressed as $Z_{C P E}=\left[Q(j \omega)^{n}\right]^{-1}$, represents an ideal capacitor and a pure resistor for $n=1$ and $n=0$, respectively, while it is associated with a diffusion process when $\mathrm{n} \sim 0.5$. All impedance data displayed in Figure $5 a$ were fitted with the EEC showed in the Figure $5 \mathrm{~b}$, with exception of those obtained for $\mathrm{cHAp} / \mathrm{p}$. For EEC used the latter samples does not have the capacitance response from the double layer film and corresponds to $R_{s}\left(R_{b} Q_{b}\right)$. The numerical evaluation of the EIS results is provided in Table 2. The percentage error associated with each circuit element was lower than $5 \%$ in all cases, reflecting the good quality of the experimental data fitting.

Table 2. Data derived from the fitting of the experimental EIS results, recorded for $\mathrm{cHAp} / \mathrm{p}, \mathrm{cHAp} / \mathrm{s}$ and $\mathrm{cHAp} / \mathrm{tsp}$ dry discs, to the electrical equivalent circuits (EECs).

\begin{tabular}{llllll}
\hline Samples & $\begin{array}{l}\mathrm{R}_{\mathrm{b}} \\
\left(\Omega \mathrm{cm}^{2}\right)\end{array}$ & $\begin{array}{l}\mathrm{Q}_{\mathrm{dl}} \\
\left(\mathrm{F} \mathrm{cm} \mathrm{cm}^{-2} \mathrm{~s}^{\mathrm{n}-1}\right)\end{array}$ & $\mathrm{n}$ & $\begin{array}{l}\mathrm{Q}_{\mathrm{b}} \\
\left(\mathrm{F} \mathrm{cm}^{-2} \mathrm{~s}^{\mathrm{n}-1}\right)\end{array}$ & $\mathrm{n}$ \\
\hline $\mathrm{cHAp} / \mathrm{p}^{[\mathrm{a}]}$ & $134.6 \mathrm{M}$ & - & - & $8.180 \times 10^{-10}$ & 0.76 \\
$\mathrm{cHAp} / \mathrm{s}^{[\mathrm{b}]}$ & $6.43 \mathrm{M}$ & $1.248 \times 10^{-8}$ & 0.77 & $1.215 \times 10^{-5}$ & 0.44 \\
$\mathrm{cHAp} / \mathrm{tsp}{ }^{[\mathrm{b}]}$ & $0.67 \mathrm{M}$ & $4.558 \times 10^{-7}$ & 0.71 & $4.863 \times 10^{-5}$ & 0.55 \\
\hline
\end{tabular}

[a] The EEC for cHAp/p is $\mathbf{R}_{\mathbf{s}}\left(\mathbf{R}_{b} \mathbf{Q}_{b}\right)$. [b] The EEC for HAp/s and HAp/tsp is displayed in Figure 5b.

The $R_{b}$ obtained for cHAp/tsp is very low $\left(6.7 \times 10^{5} \Omega \cdot \mathrm{cm}^{2}\right)$ with respect to $\mathrm{cHAp} / \mathrm{s}\left(6.4 \times 10^{6} \Omega \cdot \mathrm{cm}^{2}\right)$, which indicates that the ionic conductivity increased by one order of magnitude when the TSP process is applied. Moreover, the $\mathrm{R}_{\mathrm{b}}$ of $\mathrm{cHAp} / \mathrm{p}\left(134.6 \times 10^{6}\right.$ $\Omega \cdot \mathrm{cm}^{2}$ ) is two orders magnitude higher than that $\mathrm{cHAp} / \mathrm{s}$, evidencing that sintering also promotes charge transport. Another relevant change induced by the both the sintering and the TSP is the appearance of a second time constant $\left(\tau_{2}\right)$, indicating the creation of charge pathways inside the solid through the formation of larger crystals (Figure 5a). This observation is in perfect agreement with SEM, NMR and cyclic voltammetry results discussed above. Overall, the conductive sites in cHAp/tsp seem to arise from the re-organization of the vacancies into channels, which are formed by the dehydroxylation of the crystals during the sintering. This restructuration occurs during the TSP process and, as a result, ions are able to move along the crystals. This interpretation is in 
good agreement with results derived from other studies of HAp at high temperatures. ${ }^{[22]}$

Figure $5 c$ compares the electrical resistivity, $\mathrm{R}_{\mathrm{b}}$, of $\mathrm{cHAp} / \mathrm{tsp}$ with those of the samples prepared according to the protocol reported by Yamashita and co-workers ${ }^{[11,12]}$ (i.e. HAp/1-300, $\mathrm{HAp} / 1-800, \mathrm{HAp} / 10-300$ and HAp/10-800). As it can be seen, the $\mathrm{R}_{b}$ of $\mathrm{cHAp} / \mathrm{tsp}$ is the smallest, independently of the electric field and/or temperature used to prepare semi-permanently polarized HAp. Indeed, the $R_{b}$ of samples prepared using the procedure described by Yamashita and co-workers ${ }^{[11,12]}$ is similar to that of cHAp/s $\left(6.4 \times 10^{6} \Omega \cdot \mathrm{cm}^{2}\right)$. Again, these results point out the importance of the high temperature $\left(1000^{\circ} \mathrm{C}\right)$ in the electrical polarization step, which is necessary for the complete elimination of protons near surface layers and for the creation of both ordered structures and charge defects.

Inspection of samples three months after their preparation and polarization before the EIS measurements (Figure $5 d$ ) reveals that $\mathrm{R}_{b}$ remains practically unchanged for cHAp/tsp (i.e. $R_{b}$ increases $4 \%$ ), while the electrical resistivity of semipermanently polarized samples experiences an increment that ranges from $38 \%(\mathrm{HAp} / 10-800)$ to $69 \%$ (HAp/1-300). Overall, observations reported in this and previous subsections confirm that $\mathrm{cHAp} / \mathrm{tsp}$ shall be described as a permanently polarized cHAp.

Adsorption of pyrophosphate, triphosphate and trisphosphonate In a very recent study we examined the adsorption of sodium pyrophosphate $\left(\mathrm{P}_{2} \mathrm{O}_{7}^{4-}\right)$, sodium triphosphate $\left(\mathrm{P}_{3} \mathrm{O}_{10}^{5-}\right)$ and aminotris(methylenephosphonic acid) (ATMP), which is a phosphonic acid with chemical formula $\mathrm{N}\left(\mathrm{CH}_{2} \mathrm{PO}_{3} \mathrm{H}_{2}\right)_{3}$, onto $\mathrm{cHAp} / \mathrm{p}^{[5]}$ In order to examine how both thermal and electric treatments have affected cHAp/s and cHAp/tsp substrates, a complete adsorption study have been conducted using the same inorganic adsorbates. The concentration of adsorbate in the incubation solutions was $100 \mathrm{mM}$ for $\mathrm{P}_{2} \mathrm{O}_{7}^{4-}$ and $200 \mathrm{mM}$ for both $\mathrm{P}_{3} \mathrm{O}_{10}^{5-}$ ) and ATMP, which provided clear adsorption signals for $\mathrm{cHAp} / \mathrm{p}$ at $\mathrm{pH} 7 .^{[5]}$

The contact angle of fetal bovine serum on bare $\mathrm{cHAp} / \mathrm{s}$ and cHAp/tsp decreased after incubation, indicating that the three inorganic adsorbates were successfully adsorbed (Figure S3). The reduction of the contact angle with the adsorbate followed the same variation for the two cHAp substrates, $\mathrm{P}_{3} \mathrm{O}_{10}^{5-}<\mathrm{P}_{2} \mathrm{O}_{7}^{4-} \approx$ ATMP, suggesting that $\mathrm{P}_{3} \mathrm{O}_{10}^{5-}$ provides the higher surface energy. On the other, the XPS spectra in the $\mathrm{Na}$ 1s region reveals a peak centred at $1074.2 \mathrm{eV}$ for $\mathrm{cHAp} / \mathrm{s}$ and $\mathrm{cHAp} / \mathrm{tsp}$ treated with $\mathrm{P}_{2} \mathrm{O}_{7}^{4-}$ and $\mathrm{P}_{3} \mathrm{O}_{10}^{5-}$ (Figures 6a-b), corroborating the incorporation of these compounds. In contrast, the content of $\mathrm{Na} 1 \mathrm{~s}$ in nonincubated samples and samples incubated in presence of ATMP is null (Figure 6a). The ratios obtained using the $\mathrm{Na}$ 1s atomic percent compositions indicate that the adsorption of $\mathrm{P}_{2} \mathrm{O}_{7}^{4-}$ and $\mathrm{P}_{3} \mathrm{O}_{10}^{5-}$ is $\sim 2$ and $\sim 1.5$ times, respectively, higher for $\mathrm{cHAp} / \mathrm{tsp}$ than for cHAp/s (Table S1). A similar strategy was followed to characterize the adsorption of ATMP, which is clearly detected through the peaks at the $\mathrm{N} 1 \mathrm{~s}$ region (Figure $6 \mathrm{c}-\mathrm{d}$ ). The content of $\mathrm{N}$ 1s in non-incubated samples and samples incubated in presence of $\mathrm{P}_{2} \mathrm{O}_{7}^{4-}$ and $\mathrm{P}_{3} \mathrm{O}_{10}^{5-}$ is $\leq 0.40 \mathrm{wt}$.\%, increasing to 3.18 and 4.08 wt.\% for $\mathrm{cHAp} / \mathrm{s}$ and $\mathrm{cHAp} / \mathrm{tsp}$ samples with ATMP
(Table S1), respectively. Assuming that the amount of $\mathrm{N}_{2}$ adsorbed from the atmosphere is the same for incubated and non-incubated samples, the adsorption of ATMP is $\sim 1.4$ times higher for $\mathrm{cHAp} / \mathrm{tsp}$ than for $\mathrm{cHAp} / \mathrm{s}$. The two peaks detected at 404.3 and $402.5 \mathrm{eV}$ for the latter samples have been attributed to nitrogen atoms of ATMP with different chemical environments (i.e. free and hydrogen bonded).

Figure S4 compares the FTIR spectra of $\mathrm{cHAp} / \mathrm{p}, \mathrm{cHAp} / \mathrm{s}$ and cHAp/tsp after incubation with $\mathrm{P}_{2} \mathrm{O}_{7}^{4-}, \mathrm{P}_{3} \mathrm{O}_{10}^{5-}$ and ATMP solutions at neutral $\mathrm{pH}$. The $\mathrm{P}-\mathrm{O}-\mathrm{P}$ asymmetric stretching of $\mathrm{P}_{3} \mathrm{O}_{10}^{5-}$, which is a weak shoulder at around $890 \mathrm{~cm}^{-1}$ for $\mathrm{cHAp} / \mathrm{p}$, transforms into a well-defined band for $\mathrm{cHAp} / \mathrm{s}$ and, especially, cHAp/tsp (Figure S4a). This feature is fully consistent with XPS observations, corroborating that the sintering and TSP enhance significantly the ability of cHAp to adsorb $\mathrm{P}_{3} \mathrm{O}_{10}^{5-}$. Moreover, quantification through the ratio of integrated area of the peaks at $1016 \mathrm{~cm}^{-1}$ and $890 \mathrm{~cm}^{-1}$ indicated that the adsorption of $\mathrm{P}_{3} \mathrm{O}_{10}^{5-}$ onto $\mathrm{cHAp} / \mathrm{p}$ is 2.0 and 2.6 times lower than onto $\mathrm{cHAp} / \mathrm{s}$ and cHAp/tsp, respectively.
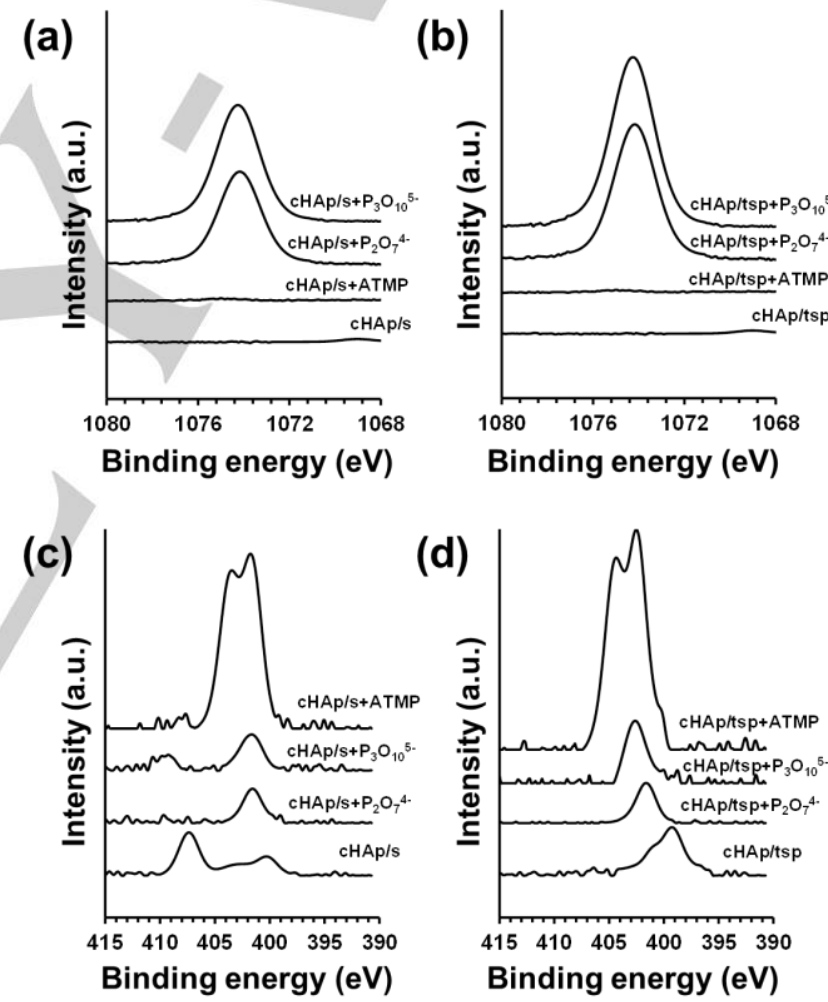

Figure 6. High-resolution $\mathrm{X}$-ray photoelectron spectra in the $(\mathrm{a}, \mathrm{b}) \mathrm{Na}$ 1s and (c,d) $\mathrm{N}$ 1s regions for $(\mathrm{a}, \mathrm{c}) \mathrm{cHAp} / \mathrm{s}$ and $(\mathrm{b}, \mathrm{d}) \mathrm{cHAp} / \mathrm{tsp}$ samples before and after incubation in $\mathrm{P}_{2} \mathrm{O}_{7}^{4-}, \mathrm{P}_{3} \mathrm{O}_{10}^{5-}$ and ATMP solutions at neutral $\mathrm{pH}$.

This feature is much less clear for $\mathrm{P}_{2} \mathrm{O}_{7}^{4-}$ since the band at 890 $\mathrm{cm}^{-1}$ remains undetectable (Figure $\mathrm{S} 4 \mathrm{~b}$ ). In this case, the only evidence of adsorption is the very weak shoulder at $740-750 \mathrm{~cm}$ 1 for $\mathrm{cHAp} / \mathrm{s}$ and $\mathrm{cHAp} / \mathrm{tsp}$, which has been attributed to the $\mathrm{P}$ $\mathrm{O}-\mathrm{P}$ symmetric stretching. The atomic percent content of $\mathrm{Na} 1 \mathrm{~s}$ detected by XPS in cHAp samples incubated with $\mathrm{P}_{3} \mathrm{O}_{10}^{5-}$ is considerably higher than in those incubated with $\mathrm{P}_{2} \mathrm{O}_{7}^{4-}$ (Table 
S1), which is consistent with FTIR observations. This has been attributed to the fact that phosphate chains of increasing size adapt better their geometry to the crystallographic positions of the ions at the cHAp surfaces.

Finally, FTIR results for the different cHAp samples incubated with ATMP (Figure S4c) reveals trends similar to those observed for $\mathrm{P}_{3} \mathrm{O}_{10}^{5-}$. The band at $900 \mathrm{~cm}^{-1}$, which corresponds to asymmetric vibrations of alkylphosphonic, is a shoulder for $\mathrm{cHAp} / \mathrm{p}$ and a well-defined peak for $\mathrm{cHAp} / \mathrm{s}$ and, especially, cHAp/tsp. This variation, which is in agreement with XPS results, evidence that the ability to adsorb ATMP increases as follows: $\mathrm{cHAp} / \mathrm{p}<\mathrm{cHAp} / \mathrm{s}<\mathrm{cHAp} / \mathrm{tsp}$. The adsorption of ATMP onto of $\mathrm{cHAp} / \mathrm{s}$ and $\mathrm{cHAp} / \mathrm{tsp}$ was estimated to be, respectively, 2.2 and 3.0 times higher than onto $\mathrm{cHAp} / \mathrm{p}$.

\section{Inorganic adsorbates affect the electrochemical and electrical properties}

Cyclic voltammograms recorded for $\mathrm{cHAp} / \mathrm{p}$ reflect that the electrochemical activity of untreated $\mathrm{cHAp}$ remain unaltered after the adsorption of $\mathrm{P}_{3} \mathrm{O}_{10}^{5-} \mathrm{a}, \mathrm{P}_{2} \mathrm{O}_{7}^{4-}$ or ATMP (Figure S5a). In contrast, electroactivity of incubated $\mathrm{cHAp} / \mathrm{s}$ and $\mathrm{cHAp} / \mathrm{tsp}$ samples is $\sim 40 \%$ and $\sim 60 \%$ higher than that of the nonincubated ones (Figures 7a-b), suggesting that tested inorganic adsorbates facilitate the exchange of ions between the mineral matrix and the PBS electrolyte solution during the oxidation and reduction processes. However, the most striking feature refers to the variation of the electroactivity against the number of redox cycles. Thus, the loss of electroactivity of non-incubated cHAp/s and cHAp/tsp after 1000 redox cycles is $\sim 72 \%$ and $\sim 60 \%$, respectively. The adsorption of $\mathrm{P}_{3} \mathrm{O}_{10}^{5-}, \mathrm{P}_{2} \mathrm{O}_{7}^{4-}$ or ATMP reduces these values drastically (Figures $7 \mathrm{c}-\mathrm{d}$ ), demonstrating that that these species provide electrochemical protection to the mineral and improve the stability. For example, for cHAp/tsp the LEA after 1000 cycles decreases from $\sim 60 \%$ to $21 \%, 27 \%$ or $29 \%$ upon adsorption of $\mathrm{P}_{3} \mathrm{O}_{10}^{5-}, \mathrm{P}_{2} \mathrm{O}_{7}^{4-}$ or ATMP, respectively. This effect is practically inexistent for $\mathrm{cHAp} / \mathrm{p}$ (Figure S5b), which has been attributed to the fact that the amount of adsorbate onto the surface of untreated cHAp is smaller than onto $\mathrm{cHAp} / \mathrm{s}$ and $\mathrm{cHAp} / \mathrm{tsp}$, as proved in the previous subsection.

Figures S6 and S7 display the EIS plots for $\mathrm{cHAp} / \mathrm{s}$ and cHAp/tsp, respectively, after adsorption of $\mathrm{P}_{3} \mathrm{O}_{10}^{5-}, \mathrm{P}_{2} \mathrm{O}_{7}^{4-}$ or ATMP, while results derived from the fitting to the EEC displayed in Figure $5 b$ are listed in Table S2. The $\mathrm{R}_{\mathrm{b}}$ determined for cHAp/s and $\mathrm{cHAp} / \mathrm{tsp}$ samples without (bare) and with inorganic adsorbates are plotted in Figures $7 \mathrm{e}$ and $7 \mathrm{f}$, respectively. The adsorption of $\mathrm{P}_{3} \mathrm{O}_{10}^{5-}$ and ATMP exerts a remarkable influence in the electronic conductivity, this phenomenon being particularly remarkable for $\mathrm{cHAp} / \mathrm{tsp}$. Thus, the bulk resistivity of $\mathrm{cHAp} / \mathrm{tsp}$ with adsorbed $\mathrm{P}_{3} \mathrm{O}_{10}^{5-}$ and ATMP was 66.7 and $69.9 \mathrm{k} \Omega \cdot \mathrm{cm}^{2}$, respectively, evidencing that such adsorbates promote the electron charge mobility inside the mineral. Structural changes obtained with the TSP treatment apparently favor the interaction with such adsorbates, forming better charge transfer channels.

\section{Conclusions}

cHAp/tsp has been prepared utilizing a TSP process according to which a constant DC voltage of $500 \mathrm{~V}(\mathrm{DC}$ field of $3 \mathrm{kV} / \mathrm{cm})$ is applied at $1000 \stackrel{\circ}{\circ}$ for $1 \mathrm{~h}$ to $\mathrm{cHAp} / \mathrm{s}$. Analyses of the chemical and structural properties of the resulting $\mathrm{cHAp} / \mathrm{tsp}$ have been evaluated using XPS, WAXD, solid state ${ }^{31} \mathrm{P}$ NMR and FTIR spectroscopy. Results evidence the disappearance of $\mathrm{HPO}_{4}^{2-}$ ions from the surface layer, which are typically identified in $\mathrm{cHAp} / \mathrm{p}$ and, specially, cHAp/s, the apparition of $\mathrm{OH}^{-}$vacancies and the enhancement of the crystallinity. However, the most distinctive characteristics of cHAp/tsp are the electrochemical properties (i.e. electrochemical activity and stability) and the electrical conductivity, which are considerably higher than those achieved by other authors ${ }^{[1]}$ applying lower polarization temperatures to samples sintered in a saturated water vapor atmosphere. Moreover, re-evaluation of samples that were polarized three months before has shown that both the electrochemical and electrical properties of the cHAp/tsp remain practically unaltered, proving that the acquired polarization effects are permanent. This represents a very important advantage with respect to previously reported strategies since the properties of samples polarized at lower temperatures $(\leq 800$ $\left.{ }^{\circ} \mathrm{C}\right)$ are very similar to those of $\mathrm{cHAp} / \mathrm{s}$ after three months.

$$
\text { (a) }
$$

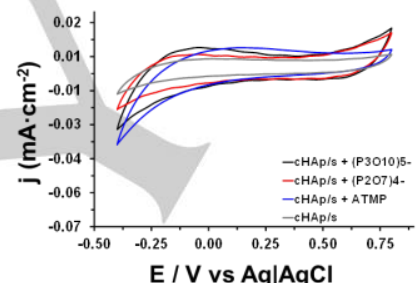

(c)

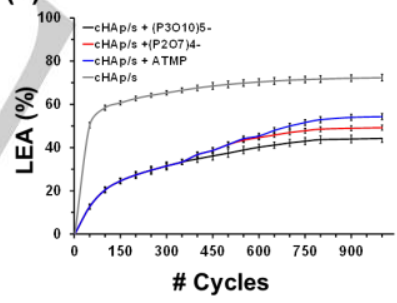

(e)

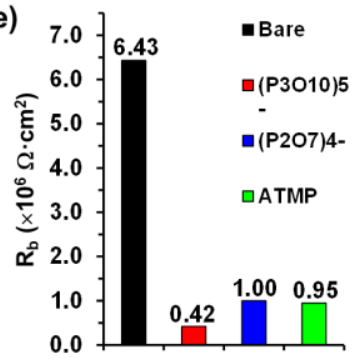

(b)

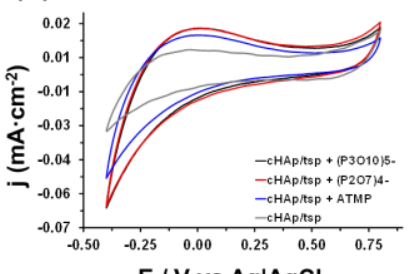

$\mathrm{E} / \mathrm{V}$ vs $\mathrm{Ag} \mid \mathbf{A g C l}$

(d)

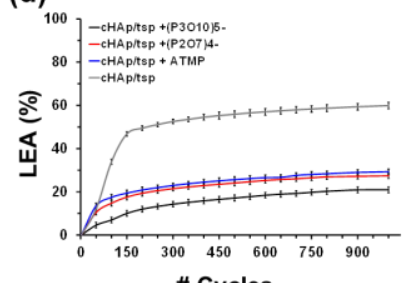

\# Cycles

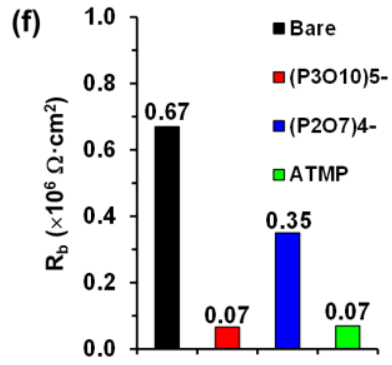

Figure 7. $(a, b)$ Control voltammograms and $(c, d)$ variation of the loss of electroactivity ( $L E A$; Eqn $\mathrm{S} 3$ ) with the number of consecutive oxidationreduction cycles in PBS for $(\mathrm{a}, \mathrm{c}) \mathrm{cHAp} / \mathrm{s}$ and $(\mathrm{b}, \mathrm{d}) \mathrm{cHAp} / \mathrm{tsp}$ samples before and after incubation in $\mathrm{P}_{2} \mathrm{O}_{7}^{4-}, \mathrm{P}_{3} \mathrm{O}_{10}^{5-}$ and ATMP solutions at neutral $\mathrm{pH}$. Comparison between the $\mathrm{R}_{\mathrm{b}}$ values determined by EIS for (e) cHAp/s and (f) cHAp/tsp before and after adsorption of $\mathrm{P}_{2} \mathrm{O}_{7}^{4-}, \mathrm{P}_{3} \mathrm{O}_{10}^{5-}$ and ATMP. 
The ability to adsorb $\mathrm{P}_{3} \mathrm{O}_{10}^{5-}, \mathrm{P}_{2} \mathrm{O}_{7}^{4-}$ and ATMP is another remarkable characteristic of cHAp/tsp. XPS and FTIR results indicate that the adsorption of inorganic phosphates and phosphonates onto cHAp/tsp is around 1.5-2 times higher than onto $\mathrm{cHAp} / \mathrm{s}$, which in turn is about twice that of $\mathrm{cHAp} / \mathrm{p}$. These results are very important for biomedical applications, as for example the fabrication of HAp scaffolds with improved phosphate and phosphonate adsorption capacity for bone regeneration. In addition, the adsorption of inorganic phosphates and phosphonates imparts electrochemical stability and reduces the electrical resistance, opening new possibilities to the electrostimulation.

\section{Experimental Section}

Materials, synthetic methods and characterization details are provided in the Supporting Information

\section{Acknowledgements}

This work was supported by B. Braun Surgical S.A. through a joint research agreement with UPC, and by MINECO-FEDER (MAT2015-69367-R and MAT2015-69547-R) and AGAUR (2017SGR359). This work is integrated within a wider research project supported by B. Braun Surgical S.A., UPC and ICFO and H. Germans Trias i Pujol.

Keywords: Bioadsorption $•$ Capacitance $\bullet$ Charge mobility • Electrocatalysis • Electrostimulation •

[1] a) S. V.Dorozhkin, M. Epple, Angew. Chem., Int. Ed. 2002, 41, 3130 3146; b) L. C. Palmer, C. J. Newcomb, S. R. Kaltz, E. D. Spoerke, S. I. Stupp, Chem. Rev. 2008, 108, 4754-4783.

[2] a) M. Y. Ma, Y. J. Zhu, L. Li, S. W. Cao, J. Mater. Chem. 2008, 18, 2722-2727; b) K. W. Wang, L. Z. Zhou, Y. Sun, G. J. Wu, H. C. Gu, Y. R. Duan, F. Chen, Y. J. Zhu, J. Mater. Chem. 2010, 20, 1161-1166; c) Q. L. Tang, Y. J. Zhu, J. Wu, F. Chen, S. W. Cao, Nanomed.: Nanotechnol., Biol. Med. 2011, 7, 428-434; d) H.-W. Kim, J. C. Knowles H.-E. Kim, Biomaterials 2004, 25, 1279-1287; e) W. Suchanek, M. Yoshimura, J. Mater. Res. 1998, 13, 94-117; f) H. Zhou, J. Lee, Acta Biomater. 2011, 7, 2769-2781.

[3] a) J. C. Elliott, P. E. Mackie, R. A. Young, Science 1973, 180, 10551057; b) G. Ma, X. Y. Liu, Cryst. Growth Des. 2009, 9, 2991-2994.

[4] a) N. Hitmi, C. LaCabanne, R. A. Young, J. Phys. Chem. Solids 1988, 49, 541-550; b) T. Ikoma, A. Yamazaki, S. Nakamura, M. Akao, J Mater. Sci. Lett. 1999, 18, 1225-1228; c) I. M. Kalogeras, A. VassilikouDova, A. Katerinopoulou, J. Appl. Phys. 2002, 92, 406.

[5] M. Rivas, J. Casanovas, L. J. del Valle, O. Bertran, G. Revilla-López, P. Turón, J. Puiggalí, C. Alemán, Dalton Trans. 2015, 44, 9980-9991.

[6] K. D. Kumble, A. Kornberg, J. Biol. Chem. 1996, 270, 5818-5822.

[7] a) P. A. Comeau, H. Frei, C. Yang, G. Fernlund, F. M. Rossi, J. Biomat. Appl. 2012, 27, 267-275; b) K. Siggers, H. Frei, G. Fernlund, F. M. Rossi, J. Biomed. Mat. Res. Part A 2010, 94, 877-885; c) K. Morita, K.
Doi, T. Kubo, R. Takeshita, S. Kato, Y. Akagawa, Acta Biomater. 2010 6, 2808-2815; d) Q. Yuan, T. Kubo, K. Doi, K. Morita, R. Takeshita, S Kato, T. Shiba, Y. Akagawa, Acta Biomater. 2009, 5, 1716-1724; e) T. Shiba, D. Nishimura, Y. Kawazoe, Y. Onodera, K. Tsutsumi, R. Nakamura, M. Ohshiro, J. Biol. Chem. 2003, 278, 26788-26792; f) Y. Hacchou, T. Uematsu, O. Ueda, Y. Usui, S. Uematsu, M. Takahashi, Y. Kawazoe, T. Shiba, S. Kurihara, M. Yamaoka, K. Furusawa, J. Dent. Res. 2007, 86, 893-897; g) S. Omelon, J. Georgiou, Z. J. Henneman, L. M. Wise, B. Sukhu, T. Hunt, C. Wynnyckyj, D. Holmyard, R. Bielecki, M D. Grynpas, PLos One 2009, 4, e5634.

[8] S. S. Kamat, F. M. Raushel, Curr. Opin. Chem. Bio. 2013, 17, 589-596.

[9] a) G. H. Nancollas, R. Tang, R. J. Phipps, Z. Henneman, S. Gulde, W. Wu, A. Mangood, R. G. G. Russell, F. H. Ebetino, Bone 2006, 38, 617627 ; b) R. G. G. Russell, F. H. Ebetino, Osteoporos. Int. 2008, 19, 733759.

[10] N. Gronich, G. Rennet, Nat. Rev. Clin. Oncol. 2013, 10, 625-642.

[11] a) M. Ueshima, S. Nakamura, M. Ohgaki, K. Yamashita, Solid State Ionics 2002, 151, 29-34; b) M. Ueshima, S. Nakamura, K. Yamashita, Adv. Mater. 2002, 14, 591-595; c) M. Nakamura, Y. Sekijima, S. Nakamura, T. Kobayashi, K. Niwa, K. Yamashita, J. Biomed. Mater. Res. 2006, 79A, 627-634; d) N. Horiuchi, M. Nakamura, A. Nagai, K. Katayama, K. Yamashita, J. Appl. Phys. 2012, 112, 074901; e) N. Horiuchi, S. Nakaguki, N. Wada, M. Nakamura, A. Nagai, K. Katayama K. Yamashita, J. Appl. Phys. 2014, 116, 014902.

[12] a) M. Nakamura, N. Hori, S. Namba, T. Toyama, N. Nishimiya, K. Yamashita, Biomed. Mater. 2015, 10, 011001; b) M. Nakamura, A. Nagai, T. Hentunen, J. Salonen, Y. Sekilima, T. Okura, K. Hashimoto, Y. Toda, H. Monma, K. Yamashita, ACS Appl. Mater. Interfaces 2009, 1, 2181-2189.

[13] N. Rivas, L. J. del Valle, P. Turon, C. Alemán, J. Puiggalí, Green Chem. 2018, 20, 685-693.

[14] L. J. del Valle, O. Bertran, G. Chaves, G. Revilla-López, M. Rivas, M. T. Casas, J. Casanovas, P. Turon, J. Puiggalí, C. Alemán, J. Mater. Chem. B 2014, 2, 6953-6966.

[15] H. Fujimori, H. Toya, K. loku, S. Goto, M. Yoshimura, Chem. Phys. Lett. 2000, 325, 383-388

[16] G. Ma, X. Y. Liu, Cryst. Growth Des. 2009, 9, 2991-2994.

[17] a) Handbook of X-ray Photoelectron Spectroscopy (Eds.: J. F. Moulder, J. Chastain), Physical Electronics Division, PerkinElmer Corporation, 1995; b) M. C. Chang, J. Tanaka, Biomaterials 2002, 23, 3879-3885.

[18] M. Jarlbring, D. E. Sandström, O. N. Antzutkin, W. Forsling, Langmuir 2006, 22, 4787-4792.

[19] Y. Wang, S. Von Euw, F. M. Fernandes, S. Cassaignon, M. Selmane, G. Laurent, G. Pehau-Arnaudet, C. Coelho, L. Bonhomme-Coury, M.-M. Giraud-Guillaume, F. Babinneau, T. Azaïs, N. Nassif, Nat. Mater. 2013, 12, 1144-1153.

[20] C. Jäger, T. Welzel, W. Meyer-Zaika, M. A. Epple, Magn. Reson. Chem. 2006, 44, 573-580

[21] a) M. B. Osman, S. Diallo-Garcia, V. Herledan, D. Brouri, T. Toshioka, J. Kubo, Y. Millot, G. Costentin, J. Phys. Chem. C, 2015, 119, 23008 23020; b) O. Bertran, G. Revilla-López, J. Casanovas, L. J. del Valle, P. Turon, J. Puiggalí, C. Alemán, Chem. Eur. J. 2016, 22, 6631-6636.

[22] a) J. P. Gittings, C. R. Bowen, A. C. E. Dent, I. G. Turner, F. R. Baxter, J. B. Chaudhuri, Acta Biomater. 2009, 5, 743-754; b) M. J. Lukic, C Jovalekic, S. Markovic, D. Uskolovic, Mater. Res. Bull. 2014, 61, 534538. 


\section{Entry for the Table of Contents}

\section{ARTICLE}

\section{Permanently polarized} hydroxyapatite, an electrocatalyst that yields amino acids by fixing $\mathrm{N}_{2}$, $\mathrm{CH}_{4}$ and $\mathrm{CO}_{2}$, shows unique electrochemical and electrical properties, which are retained even after several months. In this work we prove its noticeable ability to adsorb bioinorganic molecules, which enhance the electrochemical stability and the electrical resistance. Results open new possibilities for biomedical applications.

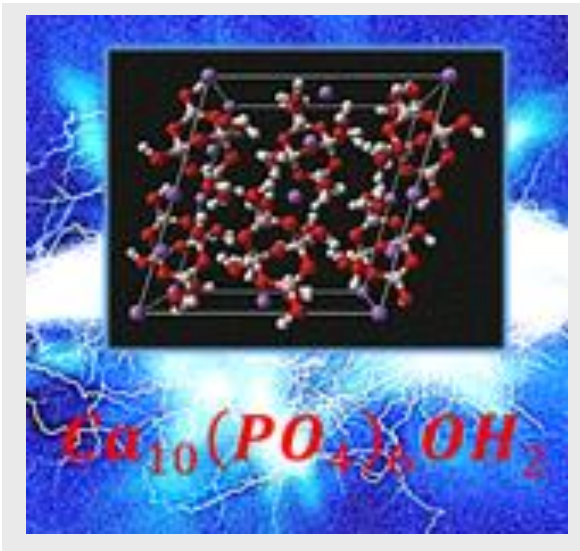

Manuel Rivas, Dr. Luis J. del Valle, Dr. Elaine Armelin, Dr. Oscar Bertran, Dr. Pau Turon, Prof. Dr. Jordi Puiggalí, Prof. Dr. Carlos Alemán*

Page No. - Page No.

Hydroxyapatite with Permanent Electrical Polarization: Preparation, Characterization and Response Against Inorganic Adsorbates 